Research article

\title{
In vitro propagation of Pueraria tuberosa (Roxb. ex Willd.) DC.
}

\author{
Bindu T. K. ${ }^{1}$, Sheema Dharmapal P. ${ }^{1}$, P. S. Udayan ${ }^{1}$, A. V. Raghu ${ }^{2}$ and Rahul R. Nair ${ }^{3}$ \\ ${ }^{1}$ Post Graduate Department of Botany \& Research Centre, Sree Krishna College, Guruvayur, \\ Ariyannur P. O., Thrissur-680102, Kerala, India \\ ${ }^{2}$ Kerala Forest Research Institute, Peechi, Thrissur-680653, Kerala, India \\ ${ }^{3}$ Aushmath Biosciences, Vadavalli, Coimbatore-641046, Tamil Nadu, India
}

*Corresponding Author: bindutksahadevan@gmail.com

[Accepted: 20 December 2017]

\begin{abstract}
Pueraria tuberosa, commonly known as Indian kudzu or 'Vidari' is an important medicinal plant belonging to the family Fabaceae. The tubers of this plant are an important constituent in many Ayurvedic formulations as a restorative tonic, immune booster and antiageing. Annual demand of Vidari by the Ayurvedic industry is 135 tonnes and industry is facing a severe scarcity of this raw material. Micropropagation technology offers large-scale production of disease-free, quality planting materials for pharmaceutical industries. A successful protocol for the in vitro propagation of $P$. tuberosa has been achieved by using nodal segments as explants. Multiple shoot induction and proliferation was obtained in Murashige and Skoog medium supplemented with $0.5 \mathrm{mg} . \mathrm{L}^{-1} \mathrm{BAP}, 0.5 \mathrm{mg} . \mathrm{L}^{-1} \mathrm{KN}$ and $2 \%$ glucose. MS medium with $1.5 \mathrm{mg} . \mathrm{L}^{-1}$ $\mathrm{KN}$ favoured maximum shoot elongation. A maximum number of roots with the highest percentage of rooting was observed on half strength MS media supplemented with $0.5 \mathrm{mg} . \mathrm{L}^{-1} \mathrm{IBA}$. Elongated shoots in half strength basal MS medium induced roots in 14 days of culture. Regenerated shoots with well-developed roots were successfully hardened with $80 \%$ survival.
\end{abstract}

Keywords: Multiple shoots - Nodal explants - Antioxidants - Vidari.

[Cite as: Bindu TK, Sheema Dharmapal P, Udayan PS, Raghu AV \& Nair RR (2017) In vitro propagation of Pueraria tuberosa (Roxb. ex Willd.) DC. Tropical Plant Research 4(3): 480-485]

\section{INTRODUCTION}

Pueraria tuberosa (Roxb. ex Willd.) DC. known as 'Mile a minute vine' is a rapidly growing perennial woody climber, distributed throughout tropical parts of India, mostly in moist regions, monsoon-forests and coastal tracts (Chopra et al. 1956). The rejuvenating drug 'Vidari' is prepared from its tuberous roots which act as a galactagogue, stimulant and emollient (Warrier et al. 1995). It has been reported to have an extensive range of medicinal properties and exhibits effective role in the treatment of leprosy, spermatorrhoea, hepatosplenomegaly, tuberculosis and cough. In ethnomedicine, the edible tubers are used to treat various ailments such as chest pain, rheumatism and fever (Jain 1991). Pueraria species are also popular for its hypoglycemic (Raghuwanshi \& Jain 2012), fibrinolysis enhancing (Verma et al. 2009), antioxidant (Pandey et al. 2007), hypolipidemic (Tanwar et al. 2008), and antimicrobial (Ratnam \& Raju 2009) properties. Some of the isoflavonoids present in the $P$. tuberosa are puerarin, daidzein, genistein and genistin (Goyal \& Ramawat 2007). Studies proved that genistein reduces systolic blood pressure and enhances aortic relaxation to acetylcholine (Vera et al. 2007). The isolated antioxidant tuberosin exhibited a variety of biological responses including influence on inflammatory pathways (Pandey \& Tripathi 2010). Dietary antioxidants lower the risk of heart diseases and neurodegenerative diseases caused by the free radicals or reactive oxygen species (ROS) generated during metabolism (Sulaiman et al. 2014).

The tubers of $P$. tuberosa are widely used in various formulations in the Indian system of Ayurvedic medicine (Goyal \& Ramawat 2007). The widespread harvesting of the medicinal plants as a source of the drug has restricted its reproduction, regeneration and survival. The growth of Pharmaceutical industries accompanied by unscientific and destructive collection, threaten the existence of many rare species. Micropropagation protocols offer an alternate method to propagate medicinal plants and produce the compounds of interest in a short period of time, without sacrifice of natural populations. 


\section{MATERIALS AND METHODS}

Plant sample and experiment designing

The nodal segments of Pueraria tuberosa were collected from 10 months old plant maintained in pots. Nodes were washed in running tap water followed by soap water treatment for 15 minutes. Nodal segments ( 2 cm length) were immersed in Bavistin (15 g.L $\left.\mathrm{L}^{-1}\right)$, cefotaxime (200 mg. $\mathrm{L}^{-1}$ and tetracycline (200 mg. $\left.\mathrm{L}^{-1}\right)$ for 40 minutes and thoroughly washed with distilled water. These explants were surface sterilized with $0.1 \%$ (w/v) $\mathrm{HgCl}_{2}$ for four minutes followed by wash with sterile distilled water. The explants were cultured on Murashige and Skoog (Murashige \& Skoog 1962) medium containing $0.8 \%(\mathrm{w} / \mathrm{v})$ agar with $2 \%(\mathrm{w} / \mathrm{v})$ sucrose and growth regulators. The $\mathrm{pH}$ of the media was adjusted and maintained to 5.7. Growth regulators like 6Benzylaminopurine -BAP (0.5 to $\left.1 \mathrm{mg} . \mathrm{L}^{-1}\right)$ and Kinetin $-\mathrm{KN}\left(0.5\right.$ to $\left.1.0 \mathrm{mg} . \mathrm{L}^{-1}\right)$ were experimented with $\mathrm{MS}$ medium at different combinations or alone for multiple shoot induction. The shoot proliferation in different combinations was recorded in the present study. The effect of Kinetin on in vitro shoot elongation was observed by inoculating the in vitro shoots on MS medium supplemented with various concentrations of $\mathrm{KN}(0.25,0.5$, 1.0, 1.5, $\left.2.0 \mathrm{mg} . \mathrm{L}^{-1}\right)$. The in vitro regenerated shoots were transferred to full strength MS and half MS with Indole Butyric Acid-IBA $\left(0.25,0.5,1.0 \mathrm{mg} . \mathrm{L}^{-1}\right)$ for rooting. For hardening, two to three weeks old rooted shoots were removed from the culture tubes, wash thoroughly and transferred to polycups containing soil and vermiculite in the ratio 1:2 and kept in mist chamber for acclimatization.

\section{Statistical analysis}

All experiments were performed with three replications, having 30 samples each. The effect of various treatments on selected growth parameters was measured quantitatively and statistically tested using analysis of variance (ANOVA) using SPSS (Statistical Package for the Social Sciences) version 11.0. The significance of the mean values of various treatments was assessed by Duncan's New Multiple Range Test (DMRT) at $\mathrm{p}<0.05$.

\section{RESULTS}

Table 1. Effect of BAP and Kinetin on shoot induction of Pueraria tuberosa.

\begin{tabular}{|c|c|c|c|c|}
\hline \multirow{2}{*}{ Treatments } & \multicolumn{2}{|c|}{ MS + Growth regulators } & \multirow{2}{*}{$\begin{array}{l}\text { \% explants showing } \\
\text { shoot formation }\end{array}$} & \multirow{2}{*}{$\begin{array}{l}\text { Number of days for } \\
\text { shoot induction }\end{array}$} \\
\hline & BAP $\left(\right.$ mg.L $\left.^{-1}\right)$ & $\mathrm{KN}\left(\mathbf{m g} . \mathrm{L}^{-1}\right)$ & & \\
\hline $\mathrm{T}_{0}$ & 0.0 & 0.0 & $0.000^{\mathrm{f}}$ & $0.000^{\mathrm{f}}$ \\
\hline $\mathrm{T}_{1}$ & 1.0 & 0.5 & $74.00 \pm 1.05^{\mathrm{b}}$ & $9.82 \pm 0.10^{\mathrm{a}}$ \\
\hline $\mathrm{T}_{2}$ & 0.5 & 0.5 & $83.00 \pm 2.10^{\mathrm{a}}$ & $6.05 \pm 0.05^{\mathrm{e}}$ \\
\hline $\mathrm{T}_{3}$ & 0.5 & 1.0 & $48.00 \pm 3.16^{\mathrm{c}}$ & $9.35 \pm 0.05^{b}$ \\
\hline $\mathrm{T}_{4}$ & - & 1.0 & $31.40 \pm 2.06^{\mathrm{e}}$ & $7.50 \pm 0.11^{\mathrm{d}}$ \\
\hline $\mathrm{T}_{5}$ & 1.0 & - & $40.00 \pm 0.05^{\mathrm{d}}$ & $8.14 \pm 0.05^{\mathrm{c}}$ \\
\hline
\end{tabular}

Note: Level of significance was measured at $p<0.05$. Column values with same superscript are not differing significantly $(\mathrm{P}>0.05)$.

Table 2. Effect of BAP and Kinetin on shoot multiplication of Pueraria tuberosa after 40 days of culture.

\begin{tabular}{llll}
\hline \multirow{2}{*}{ Treatments } & \multicolumn{2}{c}{ MS+ Growth regulators } & $\begin{array}{l}\text { Number of multiple } \\
\text { shoots per explants }\end{array}$ \\
\cline { 2 - 3 } & BAP $\left(\mathbf{m g . L ^ { - 1 }}\right)$ & $\mathbf{K N}\left(\mathbf{m g . L ^ { - 1 }}\right)$ & $00.000^{\mathrm{f}}$ \\
$\mathrm{T}_{0}$ & 0.0 & 0.0 & $09.85 \pm 0.47^{\mathrm{b}}$ \\
$\mathrm{T}_{1}$ & 1.0 & 0.5 & $17.95 \pm 0.48^{\mathrm{a}}$ \\
$\mathrm{T}_{2}$ & 0.5 & 0.5 & $08.84 \pm 0.21^{\mathrm{c}}$ \\
$\mathrm{T}_{3}$ & 0.5 & 1.0 & $06.25 \pm 0.16^{\mathrm{e}}$ \\
$\mathrm{T}_{4}$ & - & 1.0 & $08.36 \pm 0.20^{\mathrm{d}}$ \\
$\mathrm{T}_{5}$ & 1.0 & - &
\end{tabular}

Morphological changes of the nodal explants were noticed within 7 days of inoculation. No shoots were developed in explants grown on the control medium. All the plant growth regulators used induced multiple shoots singly or in combination with variable response. Subcultures were done at every 15 days interval into fresh nutrient media with same nutrient composition (Table 1). MS medium supplemented with 0.5 mg.L - $^{-1}$ BAP with $0.5 \mathrm{mg} . \mathrm{L}^{-1} \mathrm{KN}$ was found to be the most suitable medium for shoot induction from nodal explants of Pueraria tuberosa. $83 \%$ of bud initiation was observed within 6 days of culture. Increasing the concentrations of growth regulators in culture medium resulted in callus formation at the basal part of the shoots. The same hormonal combination gave the maximum number of multiple shoots in 40 days of culture (Table 2; Figs. 1 \& 
2). Multiple shoot formation with the rate of $17.95 \pm 0.48$ were observed in concentrations of BAP $\left(0.5 \mathrm{mg} . \mathrm{L}^{-1}\right)$ with $\mathrm{KN}\left(0.5 \mathrm{mg} . \mathrm{L}^{-1)}\right.$ and it can be attributed to its synergistic effect of the combination. Shoot bud elongation occurred when the shoots were placed on MS medium supplemented with different concentrations of $\mathrm{KN}(0.5$, 1.0, 1.5, 2.0, $2.5 \mathrm{mg} . \mathrm{L}^{-1}$ MS supplemented with $1.5 \mathrm{mg} . \mathrm{L}^{-1} \mathrm{KN}$ was found to be the single best treatment to achieve maximum shoot length $(6.21 \pm 0.98 \mathrm{~cm})$ and a number of leaves $(5.94 \pm 0.05)$ on cultures within 10 days. It is also evident from the results that the shoot length of $P$. tuberosa increases with increasing $\mathrm{KN}$ concentration up to $1.5 \mathrm{mg} . \mathrm{L}^{-1}$ (Table 3). In the present study, a further increase in KN concentration (2.0, $\left.2.5 \mathrm{mg} . \mathrm{L}^{-1}\right)$ had a negative effect on shoot length.
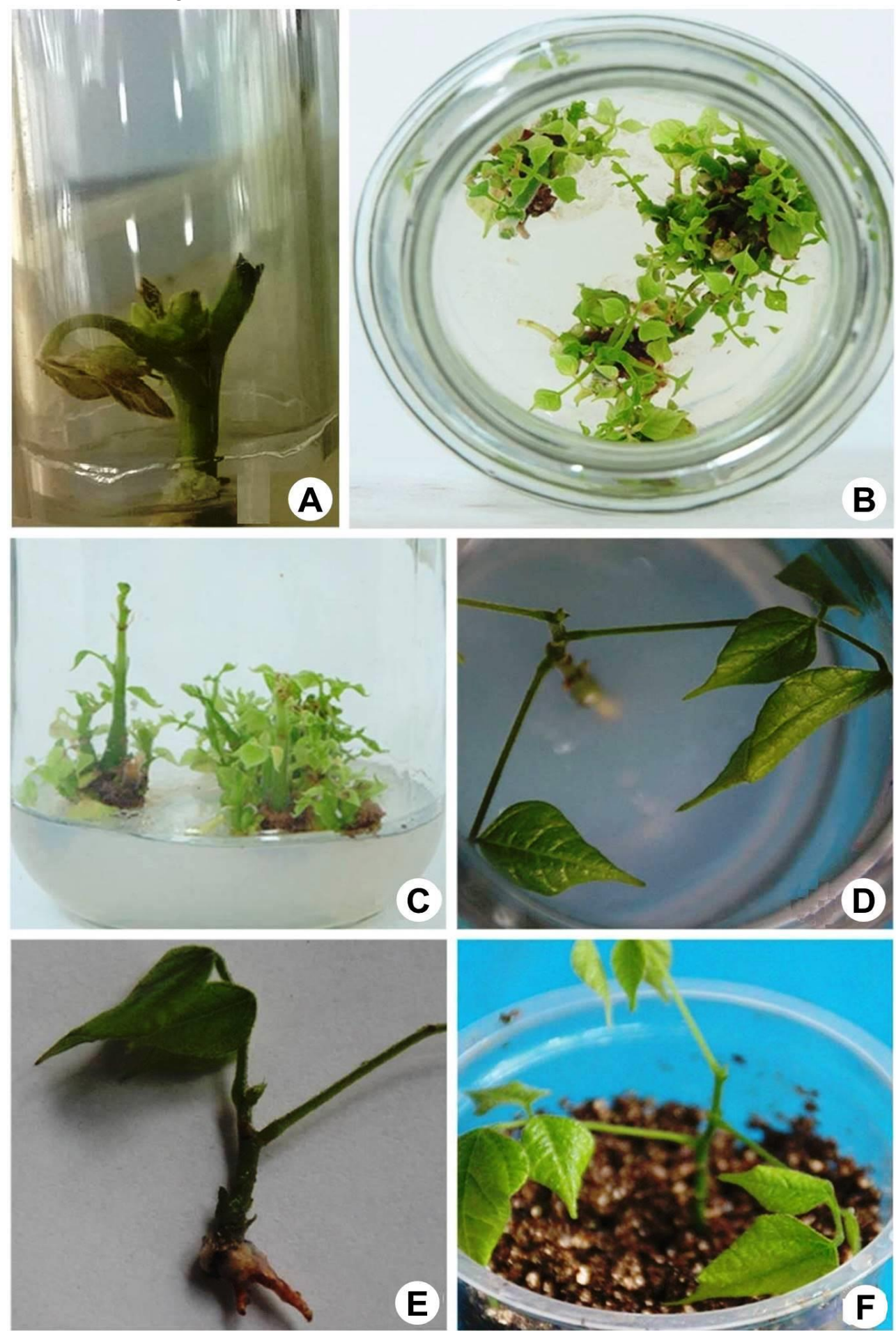

Figure 1. A, Shoot bud initiation of Pueraria tuberosa from nodal explants on MS medium supplemented with $0.5 \mathrm{mg} . \mathrm{L}^{-1}$ BAP and $0.5 \mathrm{mg} . \mathrm{L}^{-1} \mathrm{KN} ; \mathbf{B}-\mathrm{C}$, Multiple shoot induction after 40 days of culture on $0.5 \mathrm{mg} . \mathrm{L}^{-1}$ BAP and $0.5 \mathrm{mg} . \mathrm{L}^{-1} \mathrm{KN} ; \mathbf{D}$, Shoot elongation on MS medium with $1.5 \mathrm{mg} . \mathrm{L}^{-1} \mathrm{KN} ; \mathbf{E}$, In vitro rooting on half srength MS with $0.5 \mathrm{mg} . \mathrm{L}^{-1} \mathrm{IBA} ; \mathbf{F}$, Acclimatization.

www.tropicalplantresearch.com 

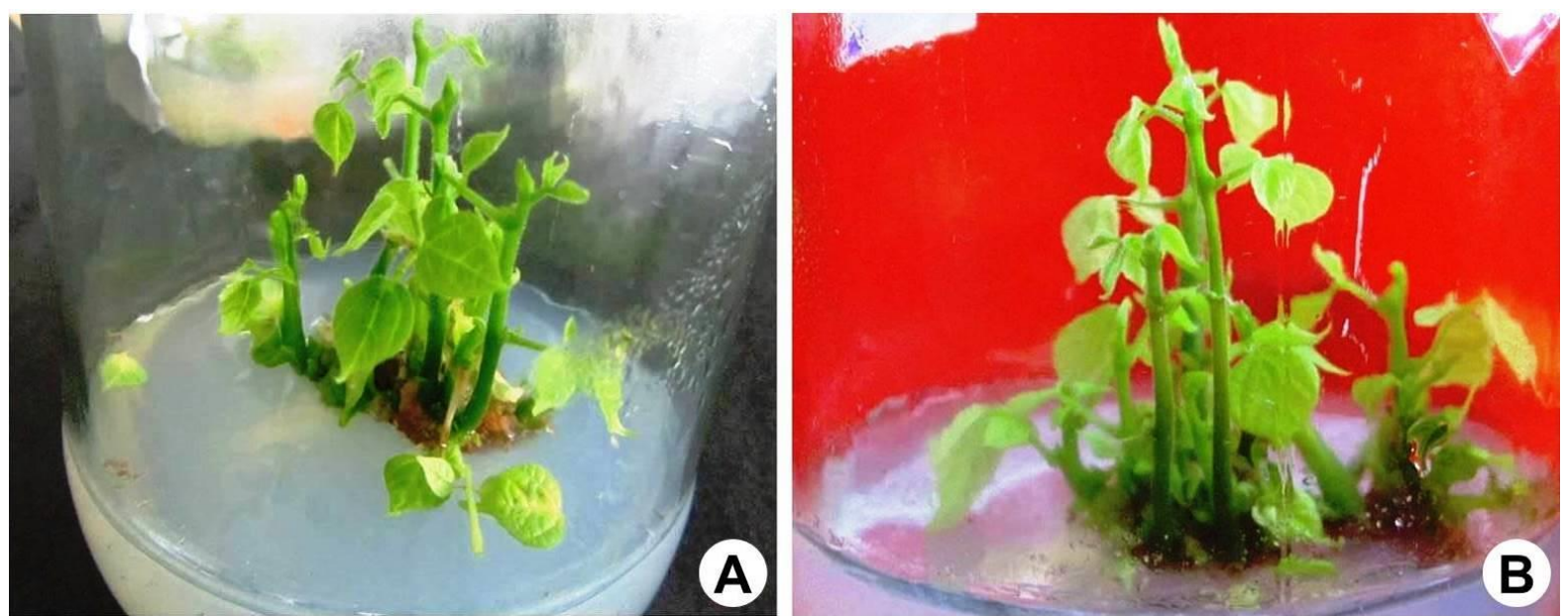

Figure 2. A, Multiple shoot induction after 40 days of culture in $0.1 \mathrm{mg} . \mathrm{L}^{-1} \mathrm{KN} ; \mathbf{B}$, Multiple shoot induction after 40 days of culture in $0.1 \mathrm{mg} . \mathrm{L}^{-1} \mathrm{BAP}$.

Table 3. Effect of KN on shoot elongation after 10 days of culture.

\begin{tabular}{llll}
\hline Treatments & MS+KN $\left(\mathbf{m g . L}^{-\mathbf{1}}\right)$ & Shoot length $(\mathbf{c m})$ & Number of leaves \\
\hline $\mathrm{T}_{0}$ & 0.0 & $0.000^{\mathrm{f}}$ & $0.000^{\mathrm{f}}$ \\
$\mathrm{T}_{1}$ & 0.5 & $2.89 \pm 0.14^{\mathrm{e}}$ & $2.35 \pm 0.05^{\mathrm{e}}$ \\
$\mathrm{T}_{2}$ & 1.0 & $3.38 \pm 0.22^{\mathrm{d}}$ & $3.35 \pm 0.10^{\mathrm{c}}$ \\
$\mathrm{T}_{3}$ & 1.5 & $6.21 \pm 0.98^{\mathrm{a}}$ & $5.94 \pm 0.05^{\mathrm{a}}$ \\
$\mathrm{T}_{4}$ & 2.0 & $4.76 \pm 0.61^{\mathrm{b}}$ & $4.05 \pm 0.05^{\mathrm{b}}$ \\
$\mathrm{T}_{5}$ & 2.5 & $4.13 \pm 0.04^{\mathrm{c}}$ & $3.15 \pm 0.05^{\mathrm{d}}$ \\
\hline
\end{tabular}

Note: Level of significance was measured at $p<0.05$. Column values with same superscript are not differing significantly $(\mathrm{P}>0.05)$.

To induce rooting, in vitro shoots were cultured on half strength MS media alone and in combination with various concentrations of growth regulator IBA. None of the in vitro shoots differentiated roots in full strength MS media without hormones. A number of roots, length of roots and number of days for root induction were observed and recorded. The differentiation of root buds varied with the growth regulator combination of the half MS (Table 4). A number of days for root induction differed significantly among the IBA concentrations in half strength MS. The number of roots and length of roots were significantly reduced on media with two levels of IBA $\left(0.25,1.0 \mathrm{mg} \cdot \mathrm{L}^{-1}\right)$. Among the different concentrations of IBA studied half strength MS media with 0.5 mg. $\mathrm{L}^{-1}$. IBA induced an optimum number of robust, healthy roots within 14 days. The micro shoots excised from in vitro cultures were successfully planted out to the soil in polypots with $80 \%$ survival. They were later planted in the field after about a month where they established well.

Table 4. Effect of Media and IBA on in vitro rooting.

\begin{tabular}{llllll}
\hline Treatments & Media MS & IBA $\left(\mathbf{m g . L}^{-\mathbf{1}}\right)$ & Number of roots & Root length $(\mathbf{c m})$ & $\begin{array}{l}\text { Number of days for } \\
\text { root induction }\end{array}$ \\
\hline $\mathrm{T}_{0}$ & Full & 0.0 & $0.000^{\mathrm{c}}$ & $0.000^{\mathrm{d}}$ & $0.000^{\mathrm{d}}$ \\
$\mathrm{T}_{1}$ & Half & 0.25 & $1.18 \pm 0.40^{\mathrm{b}}$ & $0.81 \pm 0.07^{\mathrm{c}}$ & $18.36 \pm 0.50^{\mathrm{a}}$ \\
$\mathrm{T}_{2}$ & Half & 0.5 & $3.54 \pm 0.52^{\mathrm{a}}$ & $2.96 \pm 0.10^{\mathrm{a}}$ & $14.18 \pm 0.42^{\mathrm{c}}$ \\
$\mathrm{T}_{3}$ & Half & 1.0 & $1.36 \pm 0.50^{\mathrm{b}}$ & $1.14 \pm 0.11^{\mathrm{b}}$ & $16.63 \pm 0.51^{\mathrm{b}}$ \\
\hline
\end{tabular}

Note: Level of significance was measured at $\mathrm{p}<0.05$. Column values with same superscript are not differing significantly $(\mathrm{P}>0.05)$.

\section{DISCUSSION}

After 6 weeks of culture, a maximum number of in vitro shoots (17.95 \pm 0.48$)$ was obtained on MS medium containing $0.5 \mathrm{mg} . \mathrm{L}^{-1}$ BAP with $0.5 \mathrm{mg} . \mathrm{L}^{-1} \mathrm{KN}$ which differed significantly from other concentrations and combinations of BAP and KN tested as well as in the control (Fig. 1). The cytokinins BAP and KN were effective in terms of shoot induction from nodal explants of Stereospermum suaveolens (G. Don) DC. (Trivedi \& Joshi 2014) and Costus speciosus (Raghu et al. 2006). The combinations of $0.5 \mathrm{mg} . \mathrm{L}^{-1} \mathrm{BA}$ and $0.5 \mathrm{mg} . \mathrm{L}^{-1} \mathrm{KN}$ proved to be most effective for culture initiation with healthy shoots (Shubha et al. 2016). It was reported that in vitro cultures of $P$. tuberosa showed high shoot proliferation in KN supplemented media (Rathore \& Shekhawat 2009). It has been reported that in vitro shoot induction and multiplication are largely based on media 
composition containing cytokinins as major plant growth regulators (Afshin et al. 2011). Multiple shoot formation clumps having 6-7 shoots per explants have been observed at synergistic combinations of BAP and $\mathrm{KN}$ on in vitro cultures of Achyranthes aspera (Fazlima et al. 2008). The use of comparatively lower concentration of growth regulator in present protocol is an important factor worth mentioning, as it minimizes the risk of producing genetically altered individuals (Raghu et al. 2007). It is seen that treatment with $\mathrm{KN}$ alone significantly inhibited shoot production compared to treatments with BAP. It was reported that KN was less effective on multiple shoot induction of Gentiana kurroo as compared to BAP (Sharma et al. 1993). In several medicinal plant species, BAP enhances shoot multiplication of in vitro cultures (Lakshmi \& Mythili 2003), which is in conformity with the result of our study.

Shoot length was enhanced in the presence of all tested concentrations of KN compared to control and there was a significant difference among the KN concentrations. The shoot length differed significantly among the $\mathrm{KN}$ concentrations. In the present protocol, shoot bud elongation was maximum when the multiple shoots were placed on MS medium supplemented with $1.5 \mathrm{mg} \cdot \mathrm{L}^{-1} \mathrm{KN}$. These results correspond to other reports where the best shoot length and a maximum number of nodes of Matthiola incana resulted in KN enriched media (Afshin et al. 2011). There are reports which state that $\mathrm{KN}$ promotes elongation of buds in Vigna radiata (L.) Wilczek (Chandra \& Pal 1995). The length of shoots was observed to increase with increasing concentration of Kinetin $\left(0.5-1.5 \mathrm{mg} . \mathrm{L}^{-1}\right)$. Similar finding was observed in Stereospermum suaveolens (Trivedi \& Joshi 2014) when KN supplemented medium with higher concentrations form long healthy shoots with large leaves. It is evident from the study that micro shoots failed to exhibit high shoot elongation on media with two different levels of KN $\left(2.0,2.5 \mathrm{mg} . \mathrm{L}^{-1}\right)$.

In the present study in vitro shoots rooted in different concentrations of IBA in half MS. Among the different concentrations of IBA tested, $0.5 \mathrm{mg} . \mathrm{L}^{-1} \mathrm{IBA}$ significantly favoured maximum rooting, where the average root number increased to $3.54 \pm 0.52$ with highest root induction response. These strong, short, pointed and healthy roots originated with an average length of $2.96 \pm 0.10 \mathrm{~cm}$ showed high survival rate during hardening. Half strength MS media with two levels of IBA $\left(0.25,0.1 \mathrm{mg} \cdot \mathrm{L}^{-1}\right)$ developed slim and tender roots that were damaged during transfer. In vitro shoots of $P$. tuberosa rooted in IBA supplemented half strength MS media (Rathore \& Shekhawat 2009). It has been reported that in vitro rooting in Paulownia elongata exhibited a maximum number of roots and $100 \%$ rooting on half strength MS medium supplemented with $0.5 \mathrm{mg} . \mathrm{L}^{-1} \mathrm{IBA}$ (Zayova et al. 2014). The number of roots and its length decreased with $1.0 \mathrm{mg} \cdot \mathrm{L}^{-1} \mathrm{IBA}$ supplemented media. Earlier, Nayak \& Kalidass (2016) reported similar observations in Blepharispermum subsessile.

\section{CONCLUSION}

This protocol for regeneration of Pueraria tuberosa through nodal explants is highly effective for clonal multiplication and conservation. In vitro regeneration holds tremendous potential to select, multiply and conserve medicinally important genotypes, which are a potential resource of bioactive compounds.

\section{ACKNOWLDGEMENTS}

The authors are thankful to Dr. G. Jayakrishnan, Head of the Department of Botany, Sree Krishna College, Guruvayur and Dr. E.M. Muraleedharan, Scientist, Kerala Forest Research Institute (KFRI), Peechi for providing all the necessary facilities and encouragement during the work.

\section{REFERENCES}

Afshin AH, Behzad K, Alireza T \& Sahar BZ (2011) Effect of different concentrations of kinetin on regeneration of ten weeks (Matthiola incana). Plant Omics Journal 4(5): 236-238.

Chandra M \& Pal A (1995) Differential response of the two cotyledons of Vigna radiata in vitro. Plant Cell Reports 15(3-4): 248-253.

Chopra RN, Nayar SL \& Chopra IC (1956) Glossary of Indian Medicinal Plants. CSIR, New Delhi.

Fazlima P, Kazi Z, Gulshan A, Mujib K, Saiful Azam EM, Tamanna A, Jahan \& Mohamed R (2008) In Vitro propagation of Achyranthes aspera; Effect of Cytokinins and Auxins. Journal of Biotechnology 136: S161.

Goyal S \& Ramawat KG (2007) Effect of chemical factors on production of isoflavonoids in Pueraria tuberosa (Roxb. ex Willd.) DC. Suspension culture. Indian Journal of Experimental Biology 45: 1068-1072.

Jain SK (1991) Dictionary of Indian Folk Medicine and Ethnobotany. Deep Publications, New Delhi.

Lakshmi M \& Mythili S (2003) Somatic embryogenesis and plant regeneration from callus cultures of 
Kaempferia galanga L. - A medicinal plant. Journal of Medicinal and Aromatic Plant Sciences 25(4): 947951.

Murashige T \& Skoog F (1962) A revised medium for rapid growth and bioassays with tobacco tissue cultures. Physiology of Plant 15: 473-497.

Nayak P \& Kalidass C (2016) In vitro Regeneration of Blepharispermum subsessile DC: An Endangered Medicinal Plant of Odisha, India using Cotyledon Explants. Plant Tissue Culture \& Biotechnology 26(2): 255-266.

Pandey N \& Tripathi YB (2010) Antioxidant activity of tuberosin isolated from Pueraria tuberosa Linn. Journal of Inflammation 7: 47.

Pandey N, Chaurasia JK, Tiwari OP \& Tripathi YB (2007) Antioxidant properties of different fractions of tubers from Pueraria tuberosa Linn. Food Chemistry 105(1): 219-222.

Raghu AV, Geetha SP, Martin G, Indira B \& Ravindran PN (2006) Further research on clonal propagation of Costus speciosus. Journal of Tropical Meicinal Plants 7(2): 229-231.

Raghu AV, Geetha SP, Martin G, Indira B, Ravindran PN \& Mohanan KV (2007) An improved micropropagation protocol for Bael- A vulnerable medicinal tree. Research Journal of Botany 2(4): 186194.

Raghuwanshi R \& Jain B (2012) Hypoglycemic effect of Pueraria tuberosa tubers in healthy and alloxan diabetic rats. Journal of Chemical, Biological and Physical Sciences 2: 270-272.

Rathore MS \& Shekhawat NS (2009) Micropropagation of Pueraria tuberosa (Roxb. ex Willd.) and determination of puerarin content in different tissues. Plant Cell, Tissue and Organ Culture 99(3): 327-334.

Ratnam KV \& Raju RRV (2009) Preliminary phytochemical and antimicrobial properties of Pueraria tuberosa (Willd.) DC: A potential medicinal plant. Ethnobotanical Leaflets 13: 1051-1059.

Sharma N, Chandel KPS \& Anderson P (1993) In vitro propagation of Gentiana kurroo-An indigenous threatened plant of medicinal importance. Plant Cell, Tissue and Organ Culture 34: 307-309.

Shubha T, Tiwari KL \& Jadhav SK (2016) Effect of Different Cytokinins and Media Types on In vitro Shoot Proliferation of Asparagus racemosus Willd. Plant Tissue Culture and Biotechnology 26(2): 151-157.

Sulaiman CT, Geetha SP \& Indira B (2014) Identification of phenolic antioxidants in Ipomoea mauritiana Jacq. using spectrophotometric and mass spectroscopic studies. Avicenna Journal of Phytomedicine 4 (2): 89-96.

Tanwar YS, Goyal S \& Ramawat KG (2008) Hypolipidemic effects of tubers of indian kudzu (Pueraria tuberosa). Journal of Herbal Medicine and Toxicology 2(1): 21-25.

Trivedi DR \& Joshi AG (2014) In vitro Shoot Regeneration of Stereospermum suaveolens DC. using Cotyledonary Node and Nodal Explants. Plant Tissue Culture \& Biotechnology 24(2): 235-246.

Vera R, Sanchez M, Galisteo M, Villar IC \& Jimenez R (2007) Chronic administration of genistein improves endothelial dysfunction in spontaneously hypertensive rats: Involvement of eNOS, caveolin and calmodulin expression and NADPH oxidase activity. Clinical Science 12: 183-191.

Verma SK, Jain V \& Vyas A (2009) Fibrinolysis enhancement by Pueraria tuberosa (Indian Kudzu) in patients with coronary artery disease: A placebo controlled study. Journal of Cell and Tissue Research 9: 16491654.

Warrier PK, Nambiar VPK \& Ramankutty C (1995) Indian medicinal plants, A compendium of 500 species, Vols. 1-5. Orient Longman Ltd., 160, Anna Salai, Madras.

Zayova E, Petrova M, Dimitrova L, Vasilevska-Ivanova R \& Stoeva D (2014) Effect of different auxins on in vitro rooting of Paulownia elongata Propagated Plants. Genetics and Plant Physiology 4(3-4): 155-162. 